\title{
Experimental study on the photovoltaic/thermal performance of heat pipe PV/T component with active air-cooled
}

\author{
Wang Shuang ${ }^{1,2, a}$, Luo Huilong ${ }^{1, b}$,Wang Hao ${ }^{1, c}$ \\ ${ }^{1}$ Faculty of Architecture Engineering, Kunming University of Science and Technology, Kunming \\ 6505000, Yunnan, China \\ ${ }^{2}$ Faculty of Metallurgy and Energy Engineering, Kunming University of Science and Technology, \\ Kunming 650093, Yunnan, China \\ a364766529@qq.com, bhuilongkm@126.com, '821864916@qq.com
}

Keywords: solar energy; heat transfer; PV/T components; electrical efficiency; thermal efficiency

\begin{abstract}
A heat pipe photovoltaic / thermal (PV/T) component on the basis of active air-cooled was designed and constructed. The heat pipe evaporation section was used for cooling the back plate of solar panel, and the condensation section was arranged in the air flow passage. A axial flow fan was arranged at the outlet of the air flow passage to strengthen heat transfer between heat pipe condensation section and air. The collected hot air can be used for building heating, strengthening ventilation as well as hot air drying. Under the climatic conditions in Kunming area, panel temperature, cold/ hot air temperature, electrical power, electrical efficiency, thermal power and thermal efficiency of solar PV/T component were tested and analyzed. Experimental results showed that, the PV/T component has excellent electrical and thermal performance. Under the condition of daily total solar radiation was $19.78 \sim 23.25 \mathrm{MJ} / \mathrm{m}^{2}$, the average daily electrical efficiency was between $10.84 \sim 12.21 \%$, the average thermal efficiency was $26.15 \sim 31.68 \%$, the highest panel temperature was $52.3 \sim 65.1^{\circ} \mathrm{C}$, and the hot air temperature was up to $42.3^{\circ} \mathrm{C}$.
\end{abstract}

\section{Introduction}

The conversion efficiency of solar photovoltaic cells is mostly below $20 \%$, and more than $80 \%$ of the energy reaching the surface of the solar cell is unable to be converted ${ }^{[1]}$. Most of the energy converted to thermal energy is retained inside the solar cell and causes the temperature of solar cell rise. When the temperature of solar cell is increased by $1{ }^{\circ} \mathrm{C}$, the photoelectric conversion efficiency drops by $0.4 \%$ to $0.6 \%$. In the practical operation, the temperature of the solar cell can reach $70^{\circ} \mathrm{C}$ or even higher $^{[2]}$. In 1978, Kern and Russel first proposed the concept of solar photovoltaic/thermal composite utilization $(\mathrm{PV} / \mathrm{T})^{[3]}$. The PV/T system not only improves the photoelectric conversion efficiency of the solar cell, but also outputs electric energy and thermal energy at the same time, producing two kind of benefits. Based on the theoretical study, Trond Bergene and others ${ }^{[4]}$ pointed out that the overall efficiency of the PV/T system can reach $60 \% \sim 80 \%$. Zhao Jun and others ${ }^{[5]}$ made an air-cooled $\mathrm{PV} / \mathrm{T}$ system, at the same time carried out experimental studies under the conditions of natural ventilation cooling and forced ventilation cooling respectively. Jing Shuchun and others ${ }^{[6]}$ designed a $\mathrm{PV} / \mathrm{T}$ system with aluminum square tube structure, the thermal efficiency of the system can reach $50 \%$, hot water of $39^{\circ} \mathrm{C}$ is able to be obtained at the same time.

At present, most PV/T systems are cooled by water or air. When the cooling fluid flows on the back plate of solar cell, the temperature distribution of the solar panel will be uneven, which affects the photoelectric conversion efficiency ${ }^{[78]}$. In this paper, the PV/T system cooled by heat pipe is adopted. The system has the advantages of simple structure, low price, good freeze-protection, compact structure, high reliability and long service life. In addition, the working medium in the heat pipe adopts phase change heat transfer, the temperature gradient of whole heat pipe is small, so the solar panel has good temperature uniformity ${ }^{[9 \sim 11]}$. A heat pipe air-cooled PV/T component was built, and the photovoltaic/thermal performance of the component were tested. 


\section{Design and Construction of the Heat Pipe PV/T Component}

The heat pipe PV/T component is composed of the solar panel, the gravity heat pipe, the thermal insulation layer, the air flow channel, the axial flow fan and so on. FIG. 1(a) is the installation diagram of the component with uncovered solar panel, and FIG. 1(b) shows the installed component. The component consists of a transparent glass cover plate, a solar panel, a side seal and a rear sea. Insulation layers are set on the side and the back. In the middle of the solar panel back, a rectangular air passage is opened with a partition, as well as a cold air inlet and a hot air outlet are set up. The gravity heat pipe is under the solar panel, and a certain angle of inclination should be made when the gravity heat pipe is placed, so that the condensation section and the evaporation section of the heat pipe have a relative height difference. The evaporation section is directly contacted with the backboard, and the heat-conductive silica gel is coated at the contact point to reduce the thermal resistance between the heat pipe and the solar panel. The heat pipe passes through both sides of of the flow channel partition. The condensation section pipe is placed in the flow channel in a staggered arrangement. An axial flow fan is set up at the outlet of the flow channel.

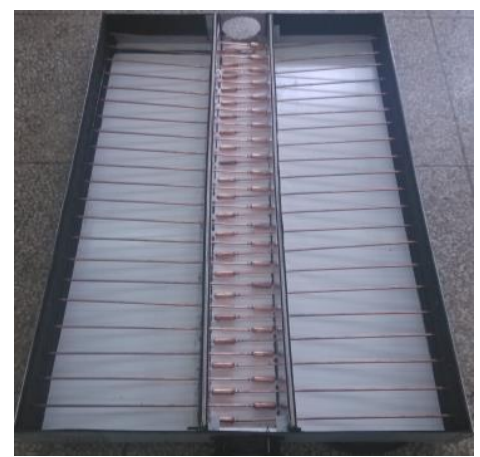

Fig. (a) Installation diagram of the PV/T component

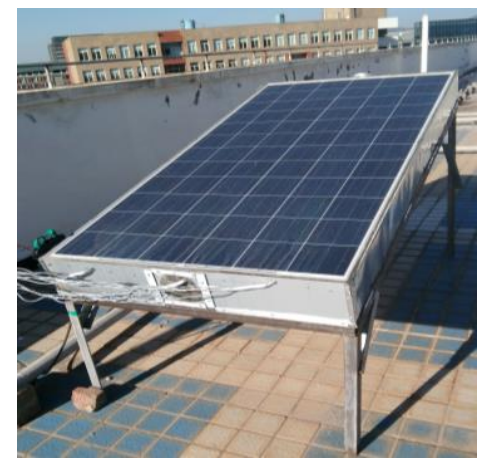

Fig.( b) Testing platform of the PV/T component

Fig.1 Physical map of the PV/T component

\section{Study on the Dynamic Performance of the Heat Pipe PV/T Component}

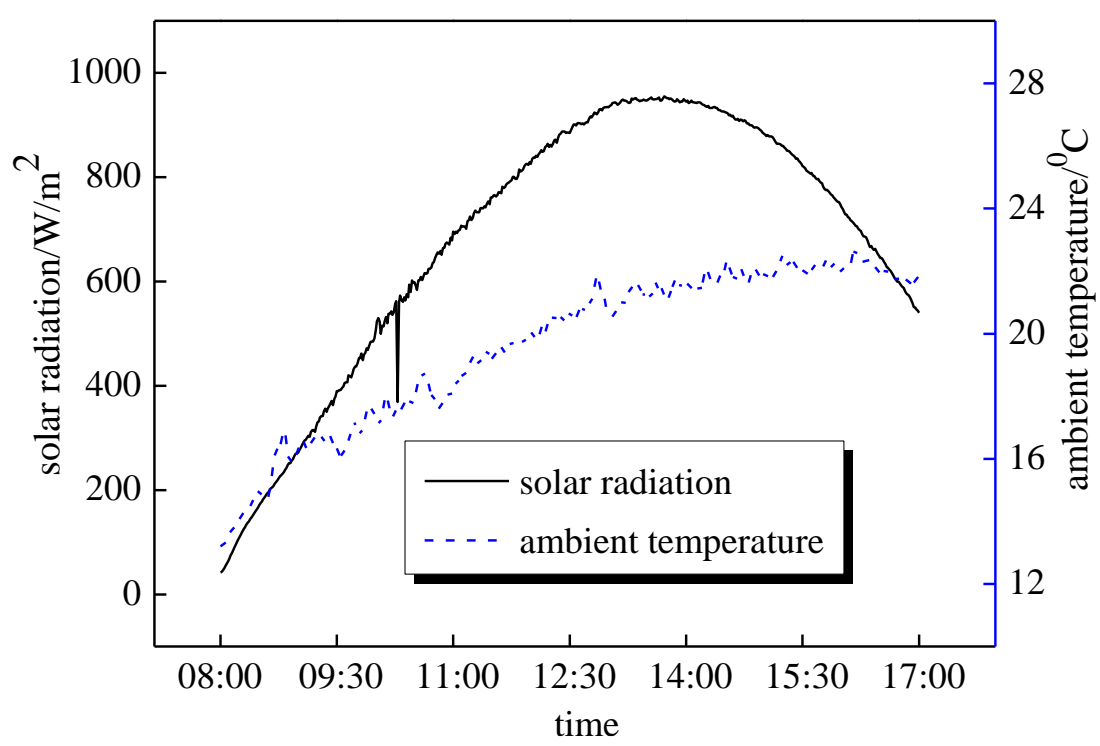

Fig. 2 The variation curve of solar radiation and ambient temperature

FIG. 2 presents the variation of solar radiation and ambient temperature on a test day. During the test, the maximum solar radiation is $951 \mathrm{w} / \mathrm{m}^{2}$, the average solar radiation is $597 \mathrm{w} / \mathrm{m}^{2}$, as well as the average ambient temperature is $19.63^{\circ} \mathrm{C}$. 


\subsection{Study on the Change of the Solar Panel 、Cold and Hot Air Temperature of the Heat Pipe PV/T Component}

FIG. 3 shows the change of the solar panel、 the cold and hot air temperature. As the graph shows, the temperature of the solar panel is $11.4 \sim 54.2^{\circ} \mathrm{C}$ from 8 a.m. to 17 p.m., which is basically the same as the change of solar radiation. From 8: 00 to 17: 00 , the temperature of cold air is $13.2 \sim 22.6^{\circ} \mathrm{C}$, and the hot air temperature is $13.4 \sim 36.6^{\circ} \mathrm{C}$. The maximum temperature difference between the cold air and the hot air is $15.3^{\circ} \mathrm{C}$. After 11 a.m., the hot air temperature remains above $30^{\circ} \mathrm{C}$. The temperature of the cold and hot air is closely related to that of the solar penal. When the PV/T component is activated in the morning, the solar radiation is low, and the temperature of the solar penal is low as well. The heat pipe does not reach the start-up temperature, so the temperature difference between the cold and hot air is not great. With the increase of the solar radiation, the temperature of the solar panel increases gradually, and the heat pipe starts to work, while the temperature difference between cold and hot air is also increasing. In the afternoon, the temperature of the solar panel decreases, and the heat transfer of the heat pipe drops. The heating effect of the air in the flow channel falls obviously, and the temperature difference between the cold and hot air declines.

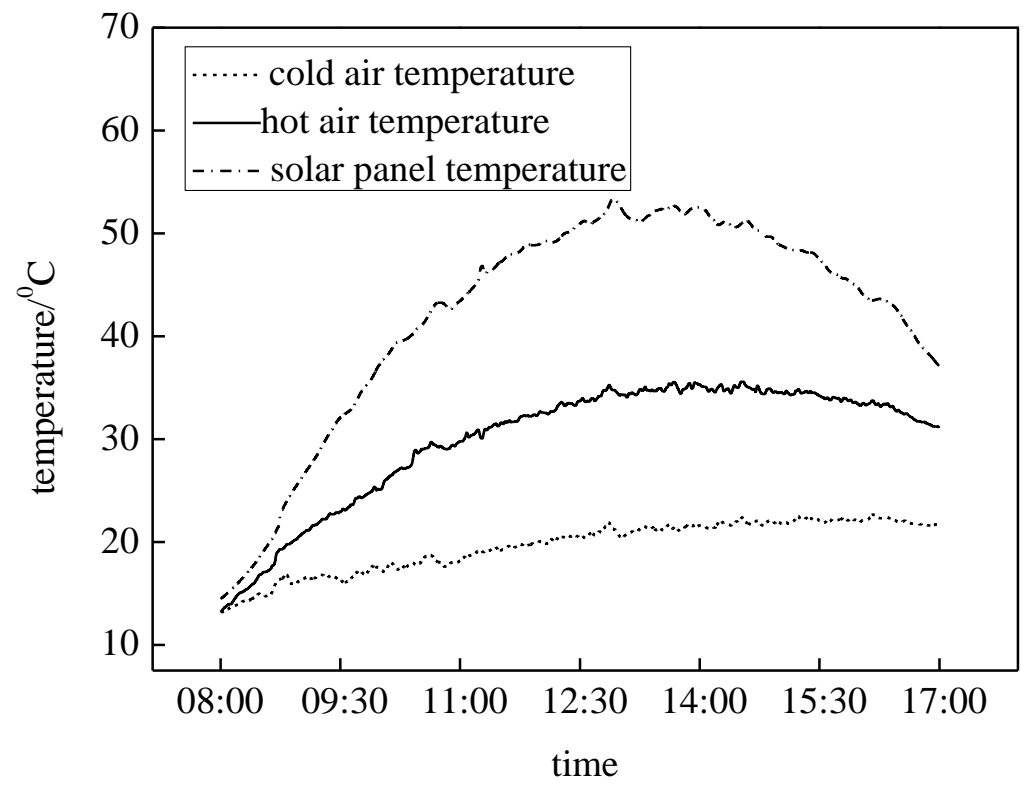

Fig. 3 The variation curve of solar panel、cold air and hot air temperature

\subsection{Study on Electrical Power and Electrical Efficiency of the Heat Pipe PV/T Component}

FIG. 4 shows the variation of electrical power and electrical efficiency of the component. The electrical power is $7.2 \sim 201.3 \mathrm{~W}$ during the test, presenting a similar change rule with the solar radiation. It can be seen that the electrical power increases with the rise of solar radiation, because when the solar radiation is within $100 \sim 1000 \mathrm{~W} / \mathrm{m}^{2}$, without considering the effect of solar panel temperature, output current of solar cell always grows with the rise of the solar radiation. But the effect of the solar radiation on the voltage of the battery is relatively small, so the output power and the solar radiation basically remain a proportional relationship.

From FIG. 4, it can also be seen that the instantaneous electrical output efficiency can reach $12.46 \%$, with an average efficiency of $10.56 \%$. The electrical efficiency increases with the growth of the solar radiation, and then experiences a slight decrease trend at noon and increases later. Until 14 o'clock, it becomes similar to the solar radiation. The main reason is that the transmittivity of the glass cover plate changes with the solar incident angle. In a day, due to the change of the solar incident angle, the transmittivity growth first and then cut down, there is a small low period at noon ${ }^{[11]}$. Accordingly, the electrical efficiency is consistent with the transmittivity trend, and it also experiences a small decrease trend at noontime. The average temperature of the solar penal increases gradually with the growth of the solar radiation, which will reduce the electrical efficiency. In the 
afternoon, the electrical efficiency experiences a small rebound with the average temperature of the solar panel gradually falls. The solar radiation has remained relatively high at the end of the test phase, so the electrical efficiency and electric power declines slowly.

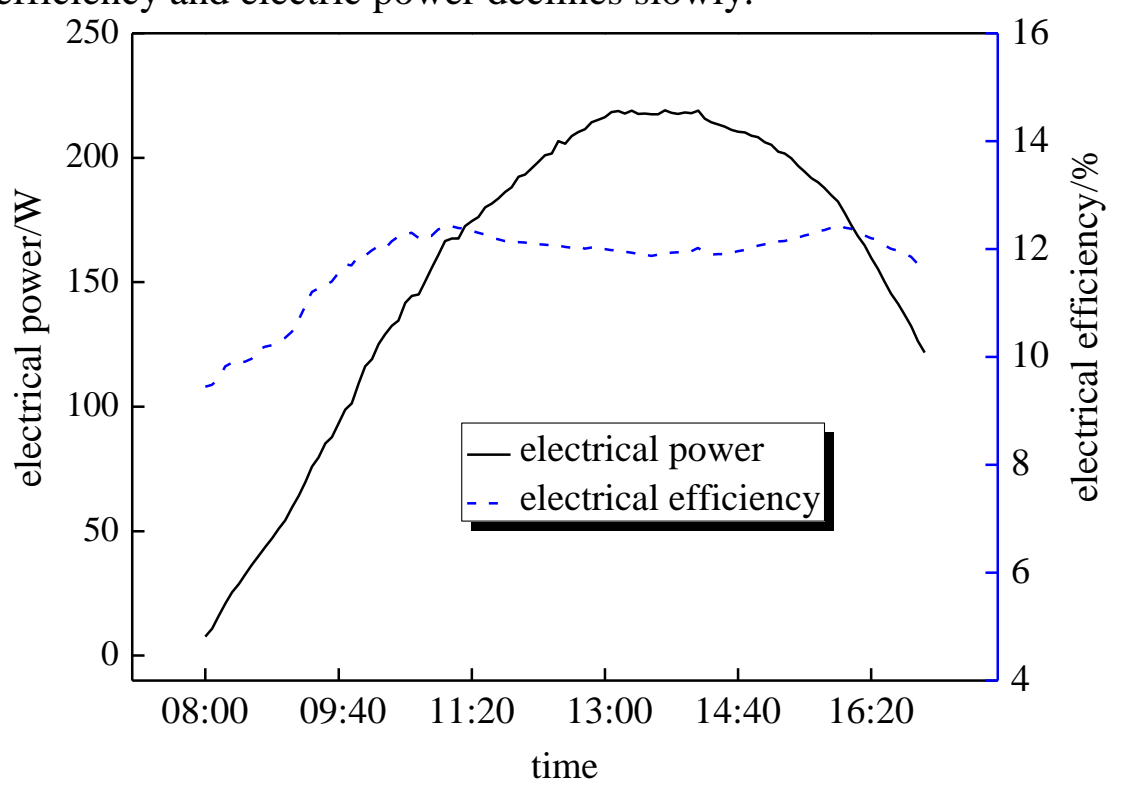

Fig. 4 The variation curve electrical power and electrical efficiency for the component

\subsection{Study on the Thermal Power and Thermal Efficiency of the Heat Pipe PV/T Component}

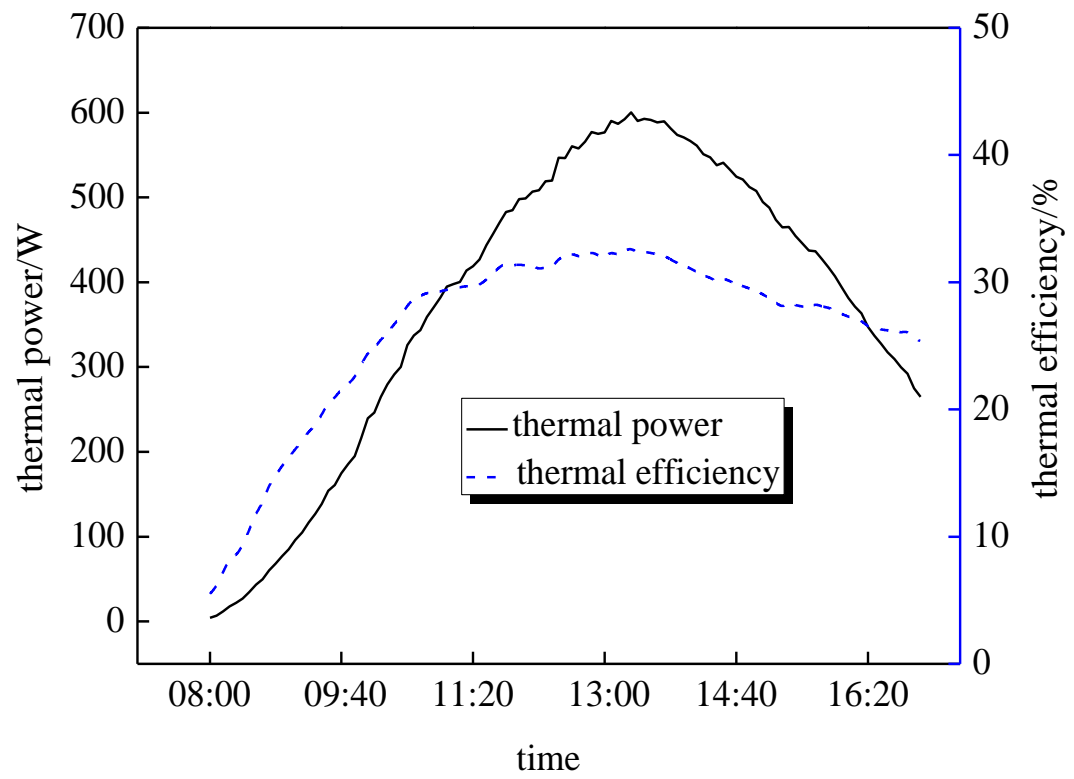

Fig.5 The variation curve thermal power and thermal efficiency for the component

FIG. 5 is a graph that shows the variation of thermal power and thermal efficiency of the component. During the test phase, the ambient temperature is not high, the thermal power of the component is $6.8 \sim 572.1 \mathrm{~W}$, the instantaneous thermal efficiency is able to reach $32.51 \%$, and the average thermal efficiency is $28.54 \%$. The dominant factor affecting the thermal power is solar radiation, so the change of the trend is basically consistent with that of the solar radiation. The curve of thermal efficiency rises first and then declines slowly, which is because the transmittivity grows with the increase of solar radiation and the thermal efficiency rises accordingly. By the end of the afternoon, the solar radiation gradually decreases, the average temperature of the component also increases to larger. The transmittivity of solar radiation declines, and the heat loss of the environment increases, so the thermal efficiency decreases slowly in the afternoon. 


\subsection{Analysis of the Daily Average Performance of the PV/T Component}

Table 1 Daily average performance of the heat pipe PV/T component

\begin{tabular}{cccccccccc}
\hline $\begin{array}{c}\text { Typical } \\
\text { test day }\end{array}$ & Weather & $t_{\text {ave }}{ }^{(1)}$ & $G_{\text {ave }}{ }^{(2)}$ & $H_{t}^{(3)}$ & $\eta_{e, \text { ave }}{ }^{(4)}$ & $\eta_{t h, a v}{ }^{(5)}$ & $t_{o, \max }{ }^{(6)}$ & $\Delta t_{\max }{ }^{(7)} t_{s, \max }{ }^{(8)}$ \\
\hline Day1 & sunny & 21.21 & 627.07 & 23.25 & 10.23 & 30.72 & 41.5 & 19.3 & 63.2 \\
Day2 & sunny & 19.63 & 597.64 & 22.37 & 10.56 & 28.54 & 36.6 & 15.3 & 54.2 \\
Day3 & sunny & 23.80 & 553.63 & 21.65 & 9.84 & 31.68 & 42.3 & 21.5 & 65.1 \\
Day4 & sunny & 17.12 & 481.05 & 20.29 & 11.12 & 26.15 & 34.2 & 12.4 & 54.9 \\
Day5 & cloudy & 19.62 & 547.42 & 22.46 & 11.37 & 28.13 & 36.3 & 14.1 & 56.1 \\
Day6 & cloudy & 18.52 & 417.80 & 21.83 & 12.21 & 26.47 & 33.1 & 13.7 & 52.3 \\
Day7 & cloudy & 20.14 & 525.30 & 19.78 & 11.47 & 29.79 & 37.7 & 16.6 & 59.0 \\
Day8 & cloudy & 21.15 & 561.21 & 22.10 & 11.88 & 29.09 & 40.6 & 18.5 & 58.4 \\
Average & - & - & - & - & 11.59 & 28.70 & 37.8 & 16.4 & 57.9 \\
\hline
\end{tabular}

(1)Daily average ambient temperature, $\left[{ }^{\circ} \mathrm{C}\right]$; (2)The average daily solar radiation, $\left[\mathrm{W} \cdot \mathrm{m}^{-2}\right]$; (3) Daily total solar radiation, $\left[\mathrm{MJ} \cdot \mathrm{m}^{-2}\right]$; (4)Daily average electrical efficiency,[\%]; (5)Daily average thermal efficiency, [\%]; (6) Maximum hot air temperature, $\left[{ }^{\circ} \mathrm{C}\right]$; (7) Maximum temperature difference between cold and hot air, $\left[{ }^{\circ} \mathrm{C}\right]$; 8) Maximum solar panel temperature, $\left[{ }^{\circ} \mathrm{C}\right]$.

Table 1 is a daily average performance test of the PV/T component under sunny and cloudy conditions in Kunming. From Table 1 , when the average daily temperature is $17.12 \sim 23.80^{\circ} \mathrm{C}$, the average daily solar radiation is $417.8 \sim 627.07 \mathrm{~W} / \mathrm{m}^{2}$, the total daily solar radiation is $19.78 \sim 23.25 \mathrm{MJ} / \mathrm{m}^{2}$, the average daily electrical efficiency is $10.84 \sim 12.21 \%$, the average daily thermal efficiency is $26.15 \sim 31.68 \%$, the highest temperature of hot air is $33.1 \sim 42.3^{\circ} \mathrm{C}$, the maximum temperature difference between cold and hot air is $12.4 \sim 21.5^{\circ} \mathrm{C}$, and the maximum temperature of the solar panel is $52.3 \sim 65.1^{\circ} \mathrm{C}$. It also can be seen from Table 1 that when the average ambient temperature is low, the highest temperature of the solar panel is low, while the electrical efficiency of the module is high, and the case of thermal efficiency is the opposite.

In this paper, air is used as the cooling medium in the PV/T component, and will not produce the freezing in the high latitudes, so that the scope of application is widened. The experimental results show that the PV/T component has excellent electrical and thermal performances, which can effectively reduce the temperature of the solar panel, moreover the hot air temperature is high, which has stronger practicability.

\section{Conclusion}

The active air-cooled heat pipe PV/T component is designed and constructed by using the excellent thermal conductivity and temperature uniformity of the heat pipe. The electrical/thermal performances are tested and analyzed. The following conclusions are drawn from this study:

1) During the sunny days, the instantaneous electrical output efficiency of the PV/T component is $12.46 \%$, the average efficiency is $11.56 \%$, the instantaneous thermal efficiency is $32.51 \%$, and the average thermal efficiency is $27.54 \%$.

2) When the daily total solar radiation is $19.78 \sim 23.25 \mathrm{MJ} / \mathrm{m}^{2}$, the average daily electrical efficiency is $10.84 \sim 12.21 \%$, the average thermal efficiency is $26.15 \sim 31.68 \%$, the highest temperature of the solar panel is $52.3 \sim 65.1^{\circ} \mathrm{C}$, and the hot air temperature is up to $42.3^{\circ} \mathrm{C}$.

3) The component is simple in structure, low in cost and has obvious advantages of electrical/thermal performances. The collected hot air can be used for building heating, strengthening ventilation as well as hot air drying.

\section{Acknowledgements}

This work was financially supported by the Natural Science Foundation(51766005), Application Basic Research Key Project of Yunnan Province (2015FA018), and Science and technology project of Yunnan tobacco companies (2015YN10). 


\section{References}

[1] Wang Li, Heng Xiangming, Pu Weihua, et al. Development progress in solar cells[J]. Journal of Yunnan University: Natural Sciences Edition, 2005, 27(5A): 473-478.

[2] Zakharcenko P, Licea J L, Perez G S A, et al. Photovoltaic solar panel for a hybrid PV/thermal system[J]. Solar Energy Materials Solar Cell, 2004, 82(1/2): 253-261.

[3] Kern E C, Russell M C, Combined photovoltaic and thermal hybrid collector systems[C]//Proceeding of the 13th IEEE Photovoltaic specialists, Washington DC, USA, 1978.

[4] Trond Bergene, Ole Martin Lovvik, Model calculations on a flat-plate solar heat collector with integrated solar cells[J]. Solar Energy, 1995, 55(6): 453-462.

[5] Zhao Jun, Qin Na, Duan Zhengqiang, The experimental research on solar cell and PV/T structure[J]. Acta Energiae Solaris Sinica, 2009, 30 (3): 327-331.

[6] Jing Shuchun, Zhu Qunzhi, Wang Wenting, Wu Mingyan. Investigation on photovoltaic/thermal solar system utilizing aluminum square tube[J]. Acta Energiae Solaris Sinica 34(9): 1639-1645.

[7] Chow T T. A review on photovoltaic/thermal hybrid solar technology [J]. Applied Energy, 2010, 87(2): 365-379.

[8] Hasan M A, Sumathy K. Photovoltaic thermal module concepts and their performance analysis: a review [J]. Renewable and Sustainable Energy Reviews, 2010, 14(7): 1845-1859.

[9] Wang Haitao, Ding Hhuaikuang, Hu Ning, Guo Erbao, The analysis on the heat transfer performance of solar gravity heat pipe[J]. Cryo.\&Supercond. 2012, 41(4): 79-82.

[10] Pei Gang, Fu Huide, Zhu Huijuan, et al. Performances study and parametric an analysis of a novel heat pipe PV/T system[J]. Energy, 2012, 37: 384-395.

[11]Fu Huide. Numerical and experimental study on a heat pipe photovoltaic/thermal system [D]: [A dissertation for doctor's degree]. HeFei: University of Science and Technology of China. 